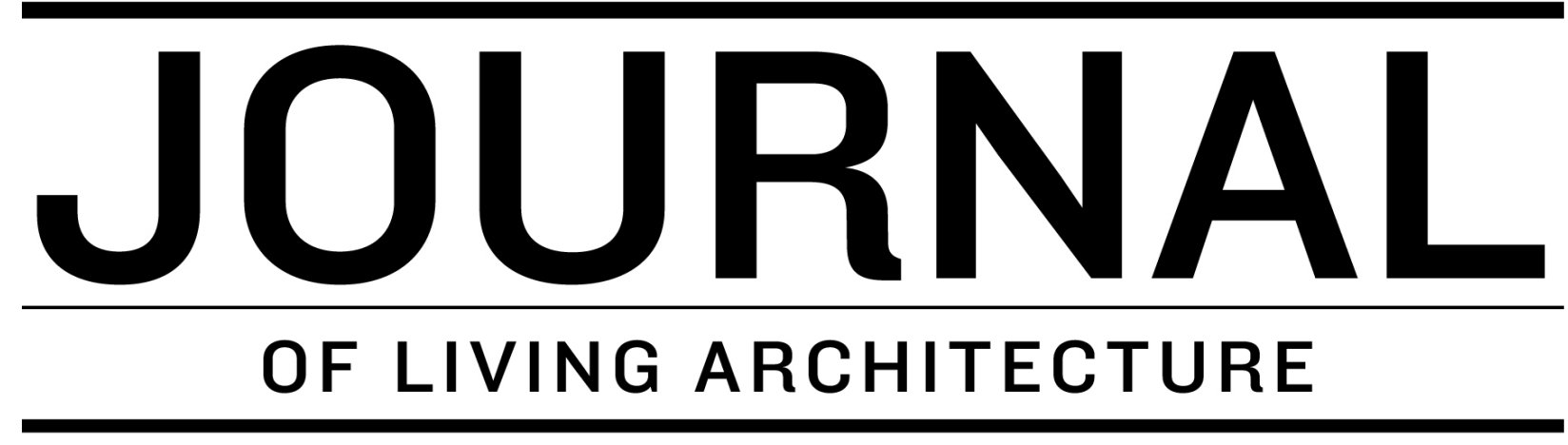

A GREEN ROOFS FOR HEALTHY CIIIES PUBLICATION

Volume 4 Number 2 Pages 1-16

2017

\title{
Deploying shipping containers for innovative living architecture design education
}

\author{
Reid Coffman ${ }^{1}$, Lee Fithian², Edwin Akins ${ }^{3}$ \\ ${ }^{1}$ Kent State University, College of Architecture and Environmental Design, Kent Ohio, USA \\ ${ }^{2}$ University of Oklahoma, College of Architecture, Norman, Oklahoma, USA \\ ${ }^{3}$ Kennesaw State University, College of Architecture and Construction Management, Marietta, \\ GA, USA. *corresponding author: rcoffma4@kent.edu
}

\begin{abstract}
Academic training and investigation for innovative living architecture demands educational settings be conceptual, experiential, and cost effective. To assist, we advance the idea that shipping containers offer an acceptable setting for faculty and students investigating kinetic forms of living architecture and opportunities for reflective thinking. Described here are three separate, uncoordinated academic engagements exploring moving, sliding and mobile green roofs and walls on shipping containers that occured in the design studio, field laboratory, and public setting. When collectively viewed, the outcomes of the projects indicate a positive use of shipping containers as conceptual and participatory spaces for living architecture education and innovation.
\end{abstract}

Key words: green roof, green wall, cargo containers, design education, mobile 


\section{INTRODUCTION}

Globalization has brought a surplus of shipping containers to certain geographic markets providing a reuse challenge for cities and design professionals (Rodrigue, et al. 2013; Kramer 2015). From this surplus, designers and business innovators are exploring container reuse in residential homes (Dillashaw 2008), hotels (Lacador 2014), student housing and offices (Tempohousing 2016), as well as hydroponic urban farms (Freight Farms, 2017) and many other building typologies: restaurants, museums \& galleries, recreation centers $\&$ gyms (Cube Depot 2017). In educational environments containers are being explored for use as classroom and research space (Dell 2016).

Although investment is supporting initial ideas for re-use of containers, it is argued that restructuring containers to accommodate permanent occupancy increases the square foot costs beyond reasonable inclusion in practice and creates limitations in building performance (Hogan 2015). Many require pre-occupancy treatment of finishes or residual pesticides for human safety and wellness (Preisser et al 2012) and larger space requirements demand stacking of containers to meet square footage needs. These criticisms may marginalize large market container re-use in cities. Yet, these same characteristics can be of high value in smaller innovative settings and projects demanding temporary occupation and deployment. When it comes to living architecture; the cargo container's structure accommodates additional weight loads; the walls and roofs possess opportunities for design innovation; and the entire unit is mobile. Exploring these attributes may broaden the reuse of shipping containers beyond permanent occupancy.

Living roofs and walls are currently being incorporated into re-used shipping containers when they are converted to small houses, offices, and shelters. A project at the 2011 Chelsea Flower Show demonstrated a green roof's potential to supply ecosystem services to a garden shed made of a refurbished container (Poteet 2016; Grass Roof Company 2016). In the United Kingdom, these explorations have led to reconfiguring cargo containers into shelters containing green roofs and habitat treatments to supply local biodiversity (Dunnett et al 2013; Green roof shelters 2016) demonstrating the customization potential of cargo containers with living architecture.

Meanwhile, within the discourse of architectural design pedagogy, the emerging paradigm of the "reflective practitioner" advocates that design students should possess a practicum experience of trial-and-error that enable a 'reflective conversation with the materials of the situation' (Schon 1984). This can occur through the conventional instructor lead studio environment or the experiential setting of a design-build project (Niedderer and Reilly 2011). Container projects are often treated as novel typologies with high levels of customization that can be realized in practice and analyzed through building science, thus shipping containers provide a potential "trial-and-error" educational experience.

The projects outlined herein attempt to re-position the container into the realm of a deployable infrastructure that is re-programmed for education, investigation and community engagement. Additionally, the re-use of the container then becomes a way to engage in a discussion of sustainability and conservation while introducing new living architecture programs and techniques to the underutilized steel shell. The techniques address ecological 
service provision of food production, distribution and provision; light energy regulation, biodiversity and habitat; and community engagement.

The three projects were carried out independently at separate colleges of architecture and design in the United States and provide an example of how different faculty and students are in engaging innovation and education. Each possessed its own agenda, teaching methods, and academic outcomes (Table 1). Common to all three projects are the exploration of movable forms of living architecture and the use of a shipping container. The first project is a design-only studio project, while the second two were design-build projects which possess a fabrication and installation component. The first project occurred in a studio setting where students focused on the conceptualization process using hand and computer drawings and models to ideate and communicate a design proposal. The second occurred as a required technical lab course to explore the concepts of the lecture course on environmental building technologies. The third was a research and community-related outreach grant that offered extra-curricular experience for students.

\begin{tabular}{|c|c|c|c|}
\hline \multirow[b]{2}{*}{ Descriptor } & \multicolumn{3}{|c|}{ Projects } \\
\hline & $\begin{array}{l}\text { 1-Studio } \\
\text { Conceptualization }\end{array}$ & $\begin{array}{l}\text { 2- Fabrication and } \\
\text { Technical }\end{array}$ & $\begin{array}{l}\text { 3- Public } \\
\text { Demonstration }\end{array}$ \\
\hline Living Architecture & $\begin{array}{l}\text { Green walls and } \\
\text { planter boxes }\end{array}$ & Green Walls and planters & Green roof \\
\hline Performance & Culinary and Water & Energy and Water & Biodiversity and Water \\
\hline Movable Functions & Hinging and Rolling & $\begin{array}{l}\text { Sliding and Removable } \\
\text { panels }\end{array}$ & Towable at <25 m.p.h. \\
\hline Teaching & Exploratory & Problem Solving & Guided Discovery \\
\hline Type of course & Design Studio & Technical lab & Extra-curricular \\
\hline Outcomes & $\begin{array}{l}\text { Ideation } \\
\text { Visualization } \\
\text { Conceptualization } \\
\text { Communication }\end{array}$ & $\begin{array}{l}\text { Detailed Design } \\
\text { Design Development } \\
\text { Fabrication } \\
\text { Installation } \\
\text { Conceptualization }\end{array}$ & $\begin{array}{l}\text { Design Development } \\
\text { Material Selection } \\
\text { Construction Drawings } \\
\text { Installation } \\
\text { Monitoring performance }\end{array}$ \\
\hline \# of students & 15 & 32 & 10 \\
\hline Level of students & Graduate & Undergraduate & Graduate \\
\hline Description & Steel & Aluminum / Plywood & Steel \\
\hline Size $(I \times w \times h)$ & $40^{\prime} \times 8^{\prime} \times 8.5^{\prime}$ & $\begin{array}{l}7^{\prime} \times 3^{\prime} \times 18^{\prime \prime} \text { Horizontal (2) } \\
20^{\prime \prime} \times 7^{\prime} \times 10^{\prime} \text { Vertical }\end{array}$ & $20^{\prime} \times 8^{\prime} \times 8.5^{\prime}$ \\
\hline Budget & n.a. & $\$ 10,000$ & $\$ 24,864$ \\
\hline Internal Funds & n.a. & $\$ 10,000$ & $\$ 13,164$ \\
\hline External Funds & n.a. & $\$ 0$ & $\$ 11,700$ \\
\hline Duration & 4 weeks & 15 weeks (Phase 01) & 12 months \\
\hline Products & & $\begin{array}{l}\text { Modules: Marine Plywood } \\
\text { Frame: TSI Aluminum Soil- } \\
\text { Sedum: Live Wall }\end{array}$ & $\begin{array}{l}\text { Soil: rooflite mc, Garland } \\
\text { Greenshield Myco Apply, } \\
\text { Prairie Moon Nursery }\end{array}$ \\
\hline
\end{tabular}




\section{PROJECT 1: CONCEPTUALIZATION IN THE DESIGN STUDIO}

Design studios provide the opportunity to explore concepts in a highly creative, lab-like atmosphere where prototyping and performance analytics test concepts prior to fabrication. The rapid processes of design generation allow for the ideation of a myriad of non-linear alternatives. The study of origami, the Japanese art of folding paper into decorative shapes, and the introduction of living architecture, helped students perceive the cargo container as a transformational opportunity which became a study scale model for creative investigation. Morphological studies showed linkages between the container's internal dimensions and movable geometries; identifying envelopes for uses that work within the confines of an object that has been optimized for shipping using existing transportation networks. Meanwhile studies in living architecture and green infrastructure provide a contextual delivery of beneficial ecosystem services.

In the urban setting, key resources are not evenly distributed, and in times of disruption, or through economic circumstance, resources may become completely unavailable. At the University of Oklahoma (Norman, Oklahoma USA), an interdisciplinary studio of five Masters of Architecture (MA) and five Masters of Landscape Architecture students (MLA) provided the opportunity to address resource concerns with solutions that draw from guerilla interventions. The studio met during normal studio hours (MWF, 1:30-5:30) for four weeks. Five self-selected teams, each with one architecture and one landscape architecture student, explored design opportunities within the shipping container constraints under the challenge to 'justify a deployable living architecture anywhere in the world'. The cost of this engagement was supported entirely within the curriculum of the College of Architecture as part of the design studio education, using a conventional tuition and fees structure to support faculty, studio space, and computer equipment. No additional costs were required.

Understanding urban equity concerns of food-the lack of availability of food - along with economic constraints - how to get fresh food to the inner city through distribution networks - presented a set of constraints for one studio team's ideation within the context of mobile distribution interventions. The team developed, The Edible Greenhouse, a mobile fresh produce growing and distribution market stand. Fresh produce is widely acknowledged as being scarce or economically unavailable to urban dwellers, and the concept sought to remedy the situation adapting a shipping container into a mobile delivery system.

The initial configuration of the 40'1 X 8'w X 8'6'h shipping container concept is shown in Figure 3. While, the modified container has working elements "folded" to meet the parametric constraints of the transportation network, the model shows the daylighting roof deployed. The daylighting roof panels would normally be collapsed for shipping to meet DOT height restrictions. Figure 4 shows the cargo container completely "unfolded" when delivered to the site and transformed into the greenhouse/produce market distribution state. Figure 5 shows how the fully deployed concept, with growing tables and walls expand into the setting around the container. The plants would be selected based on setting and time of year. For example, lettuce and greens might be grown in cooler periods and distribution would match neighborhood activities, and coordinated with a participating local organization such as a school or community center. 


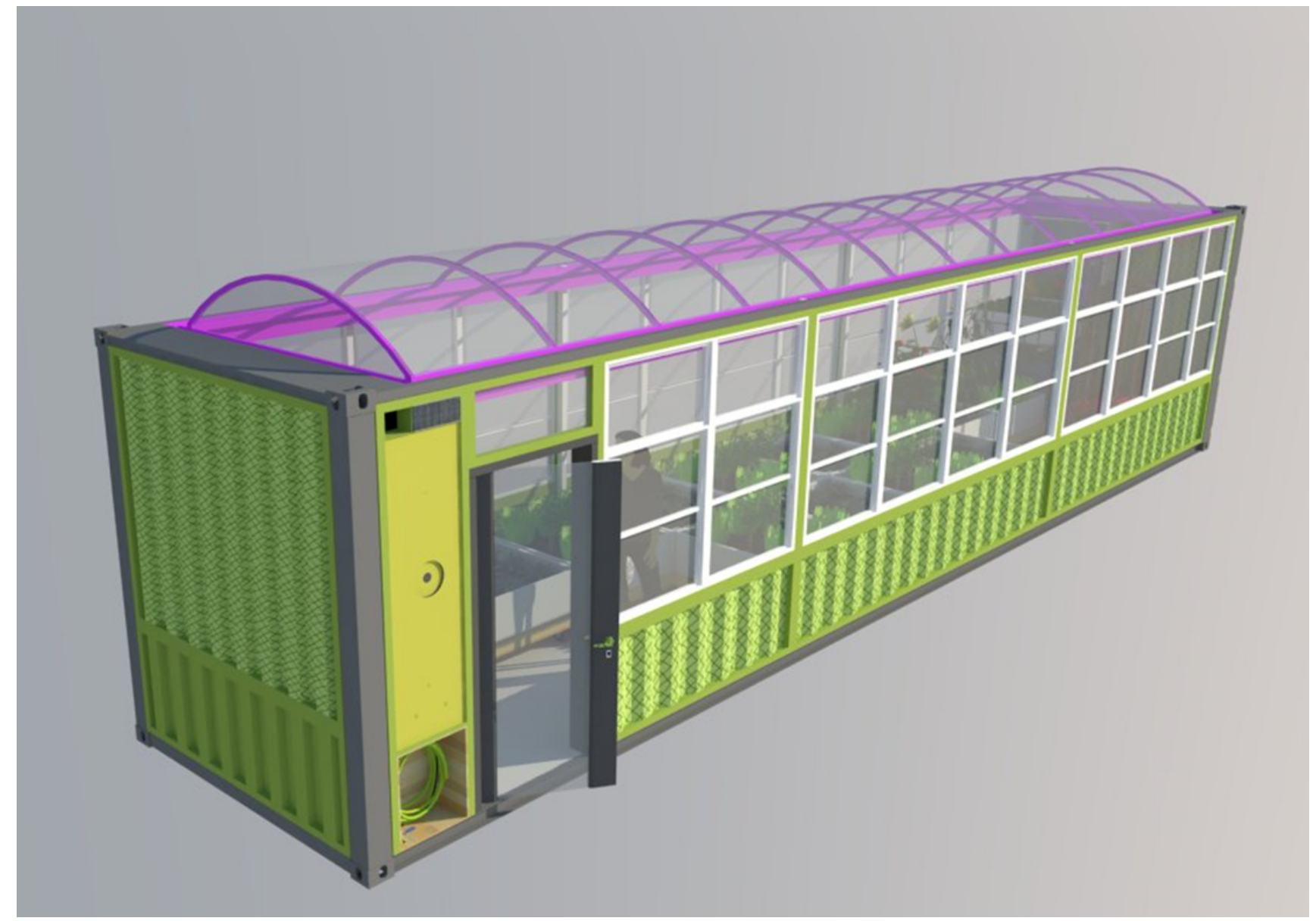

Figure 3 A fresh produce greenhouse prepared for shipping configuration

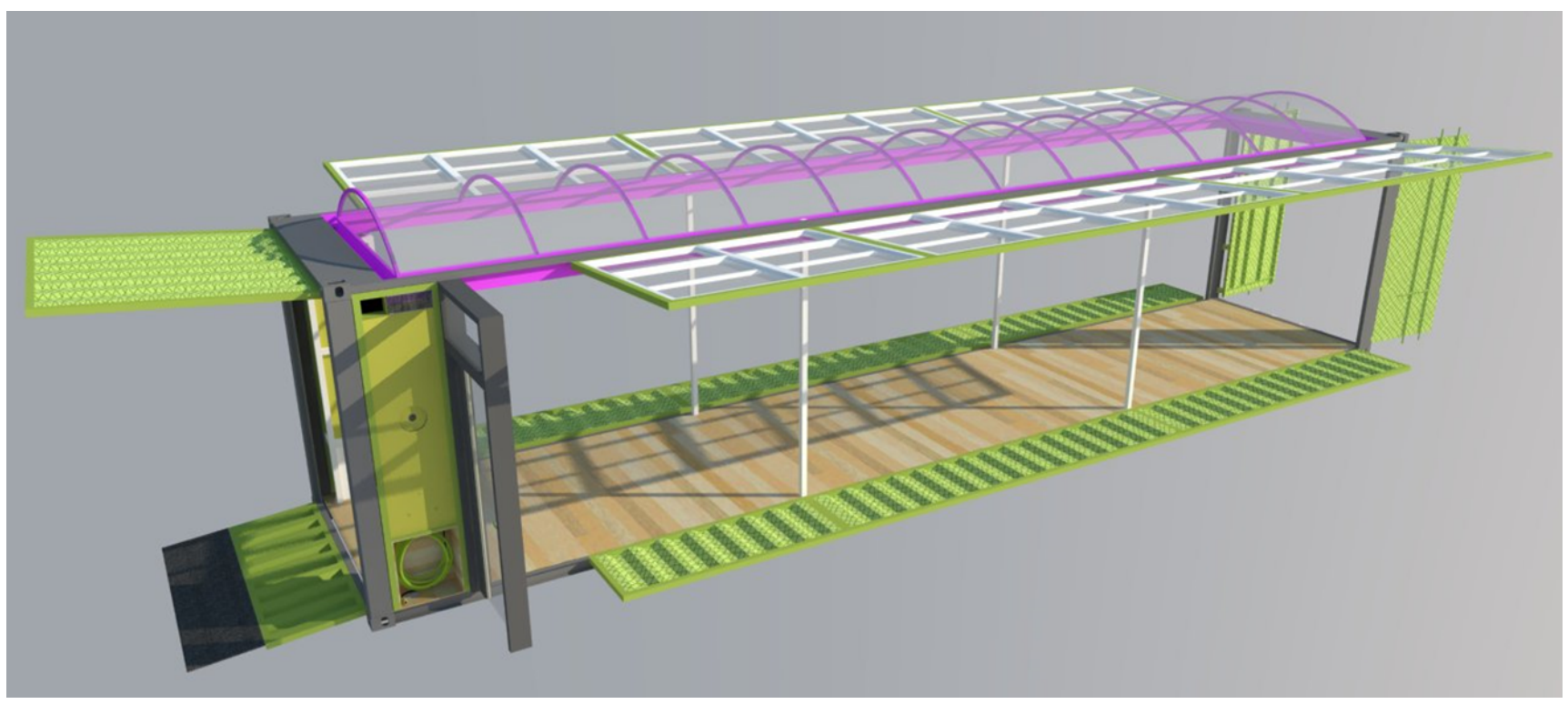

Figure 4 The kinetic edible greenhouse in the open configuration 

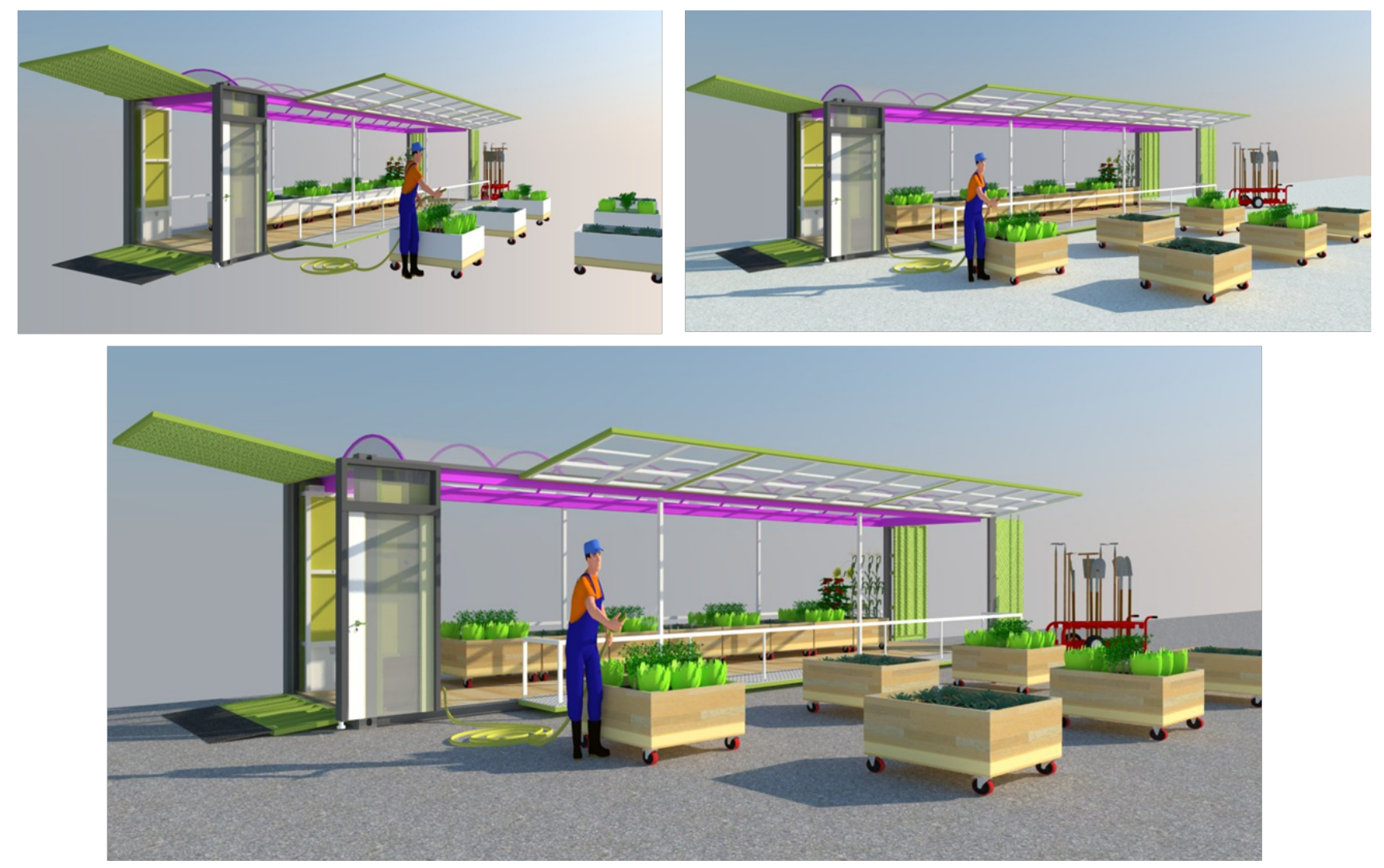

Figure 5 The fully deployed mobile edible greenhouse concept (awning support structures not shown)

\section{PROJECT 2: EXPLORATORY FABRICATION AND TECHNICAL EXPERIMENTATION}

A building skin lab (Kennesaw State University Marietta, Georgia USA) is field testing preliminary ideas for a deployable future mobile field lab. As an outgrowth of design innovations, technical research, and performance analysis of sustainable design, the building skin lab, which is located on the roof of the architecture building, hosts student led vegetal and non-vegetal building skins called ECOmponents. Currently, the lab creates a place for students to conceive, fabricate and test cross disciplinary prototypes (Figure 6). The building skin lab provides the framework for prototype ideas that may subsequently be applied to a mobile lab to study particular host sites or to educate community participants. The mobile field lab would operate by traveling to alternate locations and un-pack sustainable strategies through demonstration to provide hands-on support, education and guidance. 


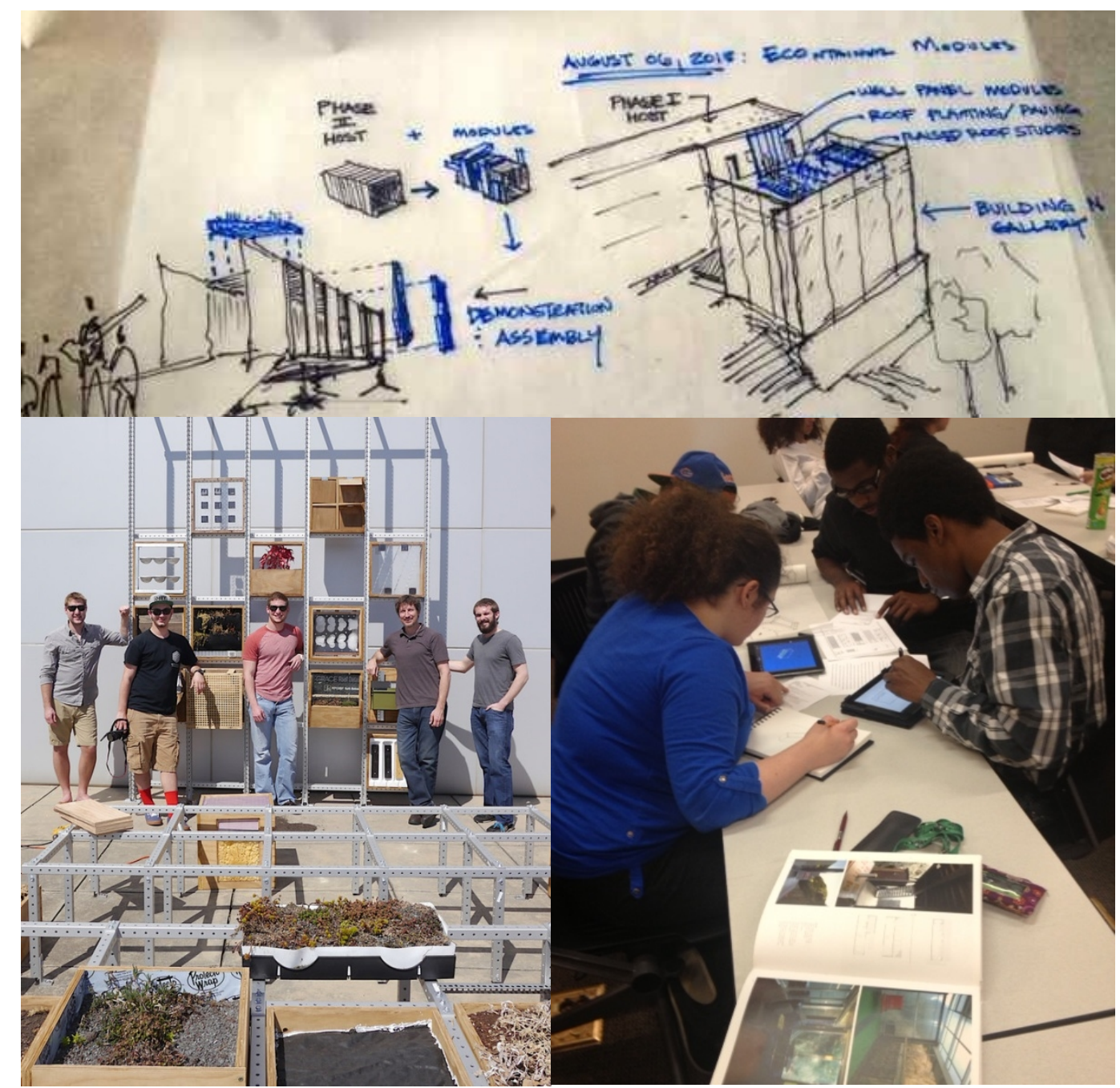

Figure 6 Building skin lab's student engaged learning and the ECOmponent prototyping space.

The most successful first phase projects from ECOmponent student module constructions, in 2013, involved soil and water studies integrated into building skin modules. Initial selections were screened vegetal walls, variable siding run-off contaminant testing, interchangeable insulated wall cavity studies, and bio-wall / algae wall panels. The stable rooftop environment allows us to create a controlled environment for research prior to deployed mobile applications. On-going testing by the Biology department regarding photosynthesis and sedum survival is being conducted and rain water irrigation lines were being installed during the summer of 2017 to integrate the potential for food production studies. This element of permanent infrastructural support can be documented for field education and work as a model for remote site education and advisement in the surrounding community.

As a continual source for hands-on design, the lab includes water and solar management in addition to building skin infrastructure frameworks and will continue to feed into the overall planning and conceptualization of the mobile container lab. This creates continual feedback and reflective thinking on the performance and design of the wall 

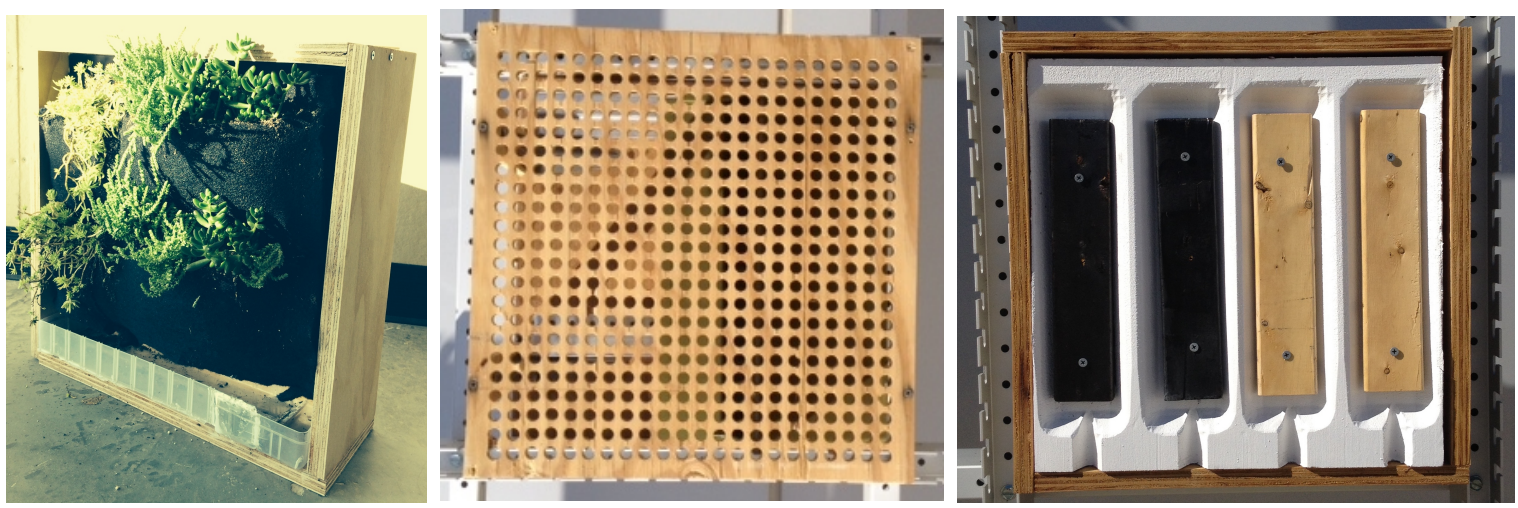

Figure 7 Student wall modules selected for further development: Felt vegetal wall study, screened vegetal wall/roof study, façade run-off study
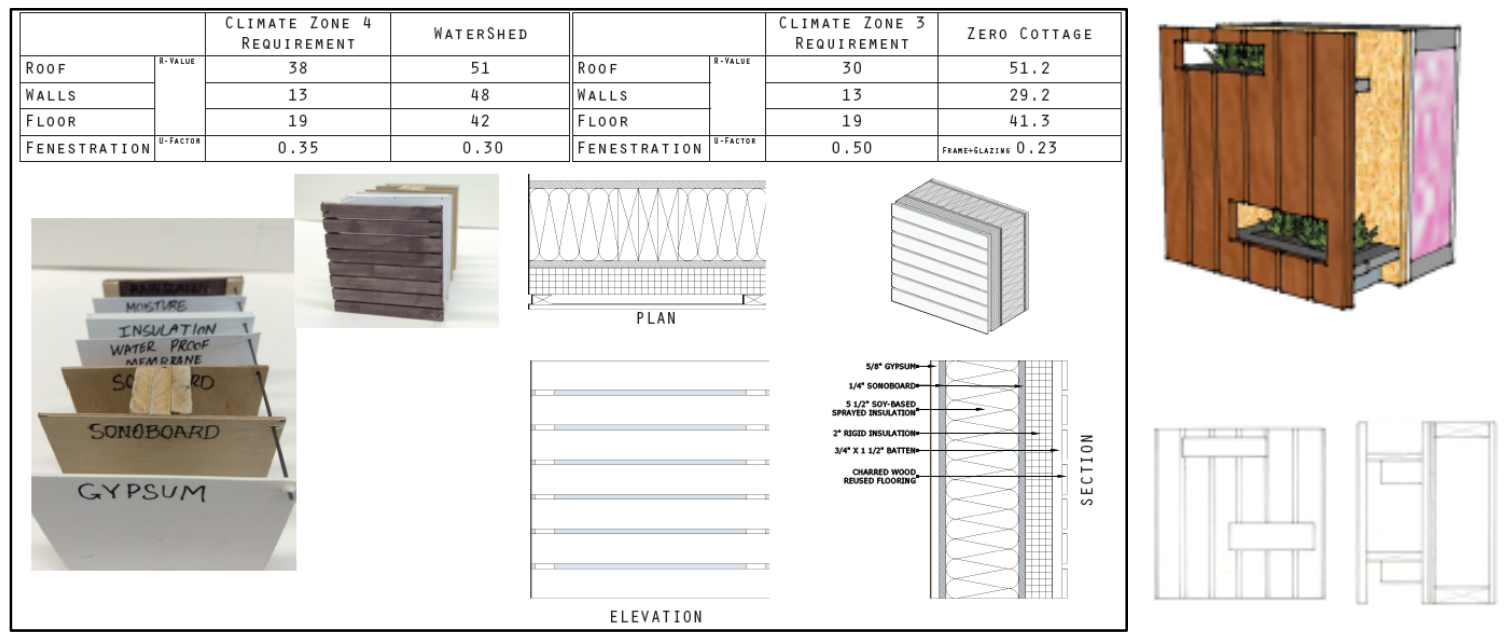

Figure 8 Students research proposals for ECOmponent façade studies and modular research components for our rooftop lab installation and container studies.

modules. Successful engagements will become more permanent installations for localized educational purposes within the College of Architecture, and other departments, prior to mobile implementation. In particular, issues unique to the Southeastern USA climate will be studied and the scaffold of the roof lab will host removable modules that allow research for soil samples and green media as well as performative building skin research. These investigations will influence the mobile lab "skins" and demonstration modules. This provides a refinement and enhancement opportunity prior to capturing our most successful work in the mobile and modifiable education environment of the container. The more permanent installations allow deeper research into green building skins related to carbon sequestration over time. This would include the analysis and monitoring of complex plant communities, the depth of soil media and deeper substrates to retain greater carbon quantities and other research agendas as outlined in other contemporary research on this subject (Wittinghill et al. 2014).

Supported by an internal grant of $\$ 10,000$, the rooftop lab and student module costs ran well below projected estimates. Figure 9 shows the material cost breakdown, where the 
framing was the highest cost item and the ECOcomponents were the lowest. The container project required site modification and preparation of $+/-\$ 6500$ prior to the acquisition of (or

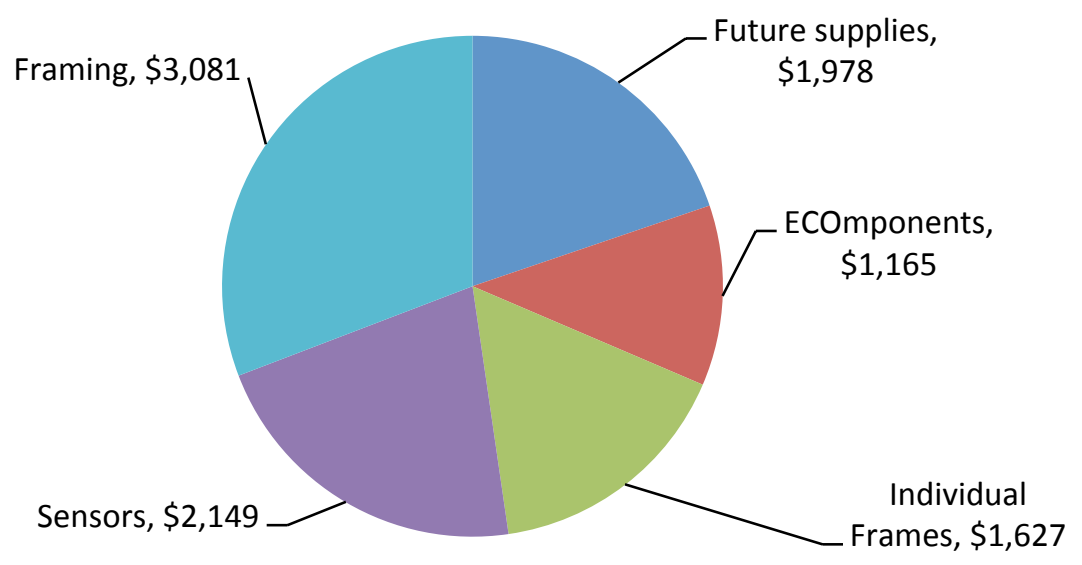

Figure 9 Cost of for the ECOmponent roof lab project $\$ 10,000$ total budget. Future supplies indicate irrigation supplies and campus facilities installation costs.

modification of the container itself. Therefore, our focus on the permanently sited building skin lab was primarily a financial decision, but it has been fruitful and allowed us to determine the very best learning outcomes that can be refined for a future mobile lab. Hopefully the integration of architecture and the natural sciences will combine within the mobile lab to educate students and the community and inspire experimentation beyond the boundaries of the classroom or university (Figure 10). Field research and site investigatory lab equipment will allow the mobile container to take site samples and provide insight into the unique ecological conditions of every host site it visits. Also, we may soon acquire and repurpose a container to demonstrate the most intriguing student research design offerings and begin to engage the community, and multiple on campus departments, in the role of building assemblies as they relate to human and environmental stewardship.

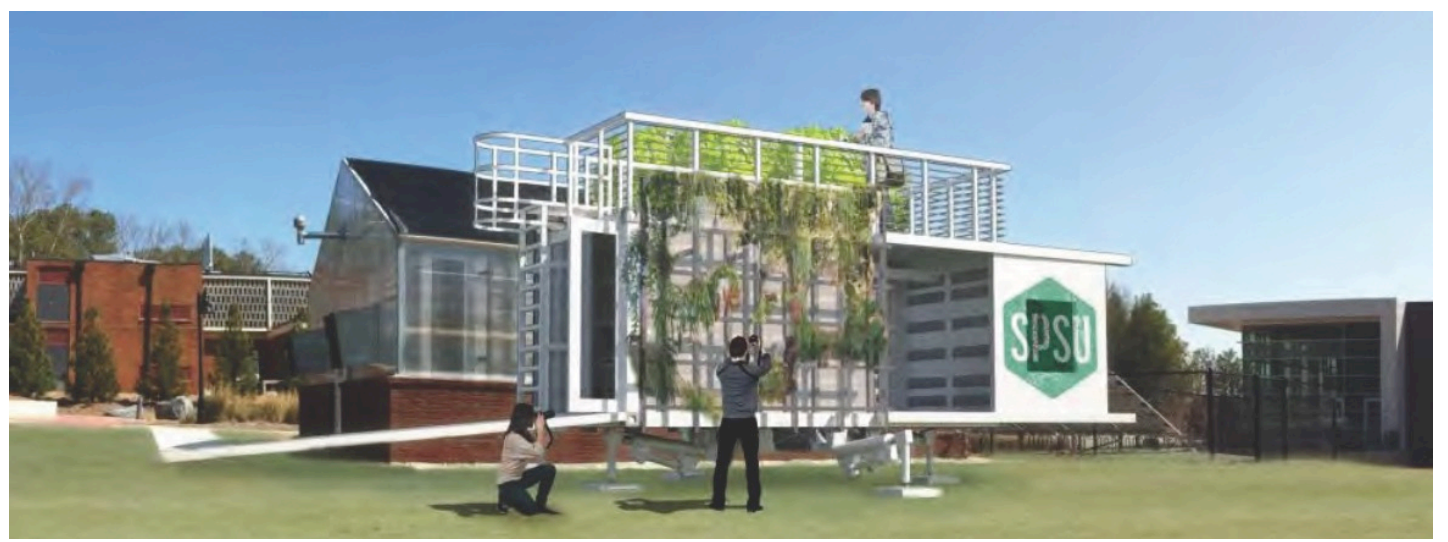

Figure 10 Student rendering of proposed container hosting the building assembly research and analysis equipment. 


\section{PROJECT 3: PUBLIC DEMONSTRATION AND RESEARCH}

Designed as a mobile lab, the 'Bike Box | Living Roof Lab' project (Kent State University, Cleveland, Ohio USA) is a full scale installation allowing faculty and students to engage in experiential learning and outreach to local partners through a design-build project focusing on public demonstration of green infrastructure (Figure 11). As a design-build project, the students participated outside their professional curricula in an initiative to design and construct for stormwater runoff and local biodiversity. A unique programmatic goal required the entire shipping container being loaded onto a flatbed tow-truck and moved at low speeds to different locations.

The pedagogical goals of the project are to offer experiential learning and create an office scenario for project execution. The project funds hired 5 student positions: Project Manager, Design Lead, Construction Lead, Communications Lead and Operations Lead. All members must assist at least one other Lead and each of the five leads recruited additional volunteers to assist in varies stages of the project: Conceptualization $>$ Design Development $>$ Construction Documentation $>$ Material Supply $>$ Fabrication $>$ Installation $>$ Establishment. The students held daily project meetings where the Leads could interact with one another to determine how decisions affected their particular responsibilities and workflows. The instructor guided the projects general direction and daily informal discussions were led by the Project Manager with questions such as: "what have you been doing": "what are you currently working on"; and "what were you planning to work on" which gave them a chance to respond to one another and stay updated on each team members working goals. This approach exposed the team to two-way communication and helped the group overcome common problems such a material substitutions and deliver and construction sequencing. Also, they were able to speak and work directly with living architecture representatives and material suppliers.

As for its mobility, the Bike Box | Living Roof Lab will be moved from its current location to a street-side parking lot to better service bicycle traffic of local businesses. This entails winching the shipping container onto an auto towing flatbed trailer that requires the unit to be tilted at a 40 degree angle. Once horizontal and secured on the auto-tow truck, the project can be towed to new locations at speeds under $25 \mathrm{~m} . \mathrm{p}$.h. To prevent slumping of the substrate during winching, the green roof is designed with an extra 2" parapet and 3 evenly distributed metal partitions. The major vegetation can be pruned during dormancy (winter) to travel longer distances. If required to travel a very long distance, a "bonnet" or tarp can be attached over the green roof. Equipment used in education and scientific monitoring is removable. Super signage is permanently integrated with the structure to withstand relocation. 


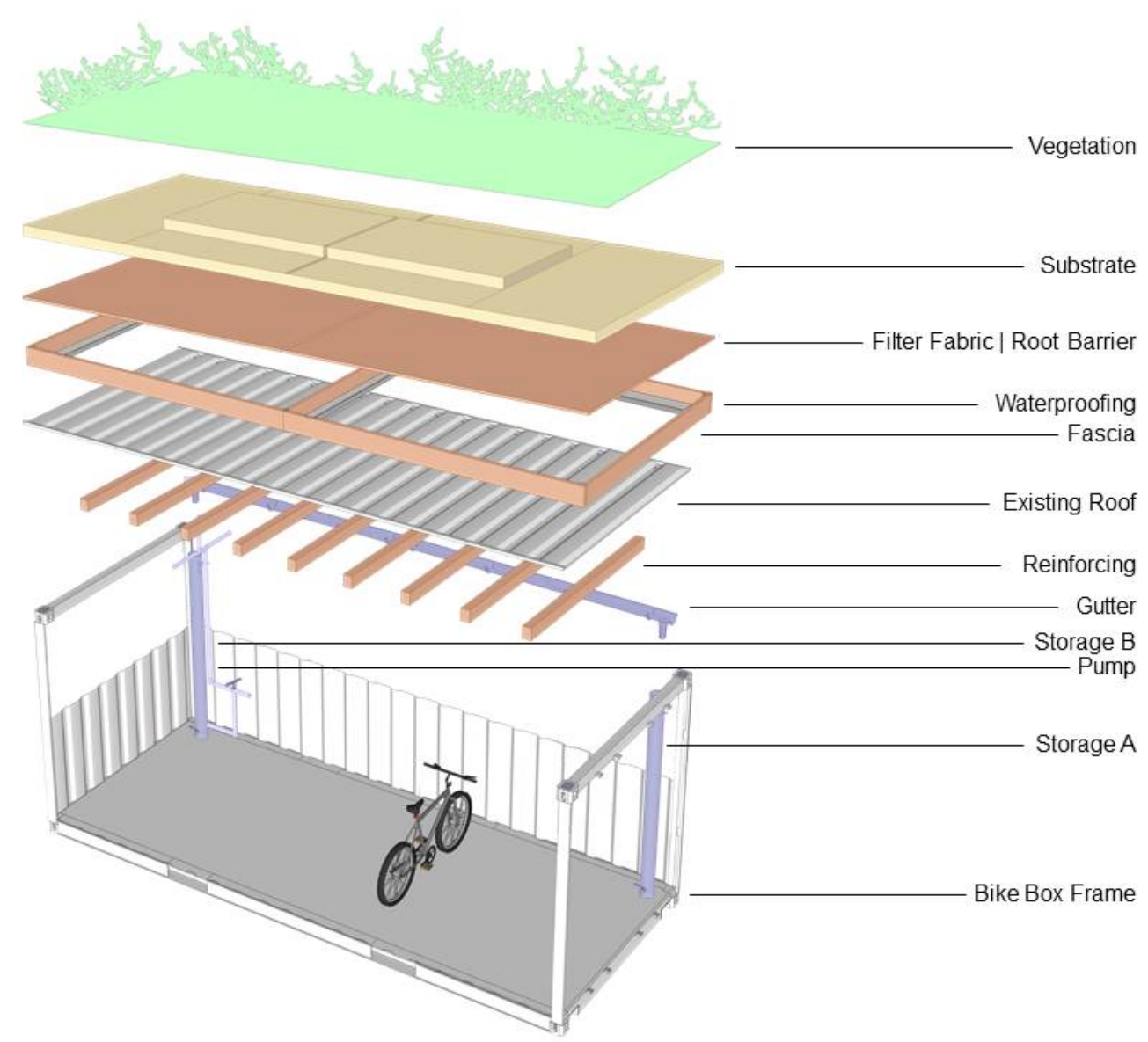

Figure 11 The Bike Box | Living Roof Lab schematic drawing was conceptualized by students, local partners and fabricators for university research and outreach opportunities (Cleveland, Ohio, USA).

The project occurred through partnership that leveraged local funding for 'high visibility' green infrastructure projects. Post installation, the project is being used for student and faculty research and teaching. The overall partnership helps facilitate local research activities for enrolled university students to record water and plant data, interact with local stewards, and host visitors (Figure 12). Research on the supply of ecosystem services is ongong. In particular the project is looking at stormwater co-benefits, including the water runoff quality and the survival and establishment of endangered plant species. Currently, various native plants are surviving and one Ohio endangered species, Prairie violet (Viola pedatifida), has shown successful establishment and potential adaptability to the green roof environment (Figure 12c). Meanwhile, native culinary species are being investigated for establishment and harvesting potential by the adjacent restaurant.

In addition, the project's outcomes extend beyond the initial student design and construction team. In 2014 the project received state recognition in a student design category by the Ohio Chapter of the American Society of Landscape Architecture. Frequently, students and faculty host campus visitors from across the USA and abroad at the project, such as National Science Foundation Undergraduate Student Fellows (12a). For outreach to public audiences, a local non-profit partner, LAND studio, advocates for the project and continues to advance the idea of more bike boxes, while the adjacent local business Happy Dog Tavern 

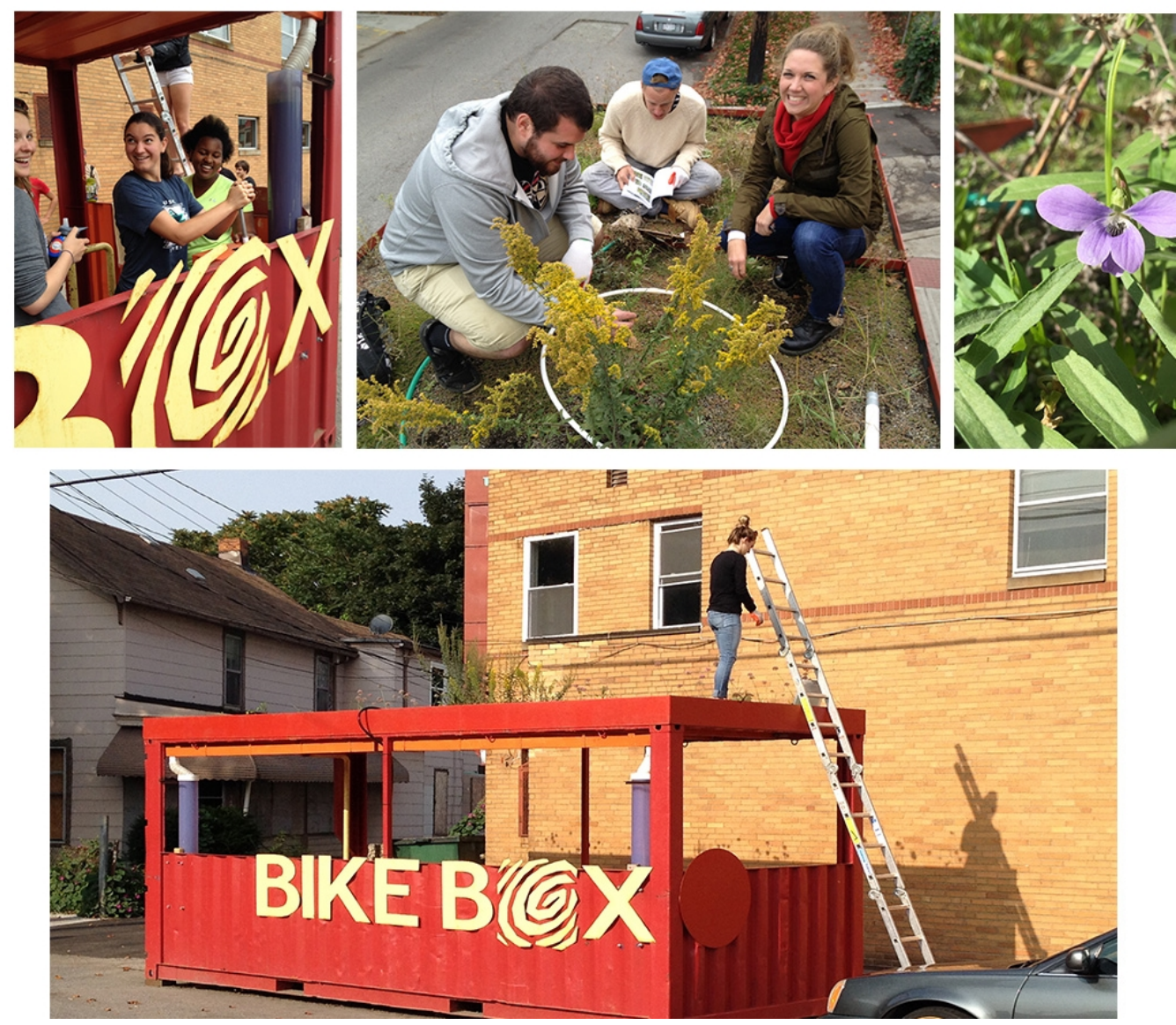

Figure 12 The Bike Box | Living Roof Lab provides university research and outreach opportunities (Kent State University, Cleveland, Ohio, USA). Shown above clockwise are (a) traveling National Science Foundation undergraduate's fellows, (b) curricular studies for enrolled students, (c) investigations of the endangered species Viola pedatifida and (d) local stewardship volunteerism.

supports and informs the design/research team of activities to local patrons and neighborhood citizens through lectures and talks. Of course, it is used daily by local bicyclists.

The total project budget was $\$ 24,864$; of which $\$ 11,700$ was secured in a competitive grant funded program run by the local water agency (Northeast Ohio Regional Sewer District) and several philanthropic and non-profit collaborators (Figure 13). The sponsorship supported the retrofitting of the bike-box with a green roof. Funds were used for student summer salaries (\$500-1000) and materials. The student team had a project manager, design lead, construction lead, graphics communications lead, education lead, and several volunteers. In-kind services of $\$ 13,667$ for faculty time and fabrication provided a large portion of the budget. 


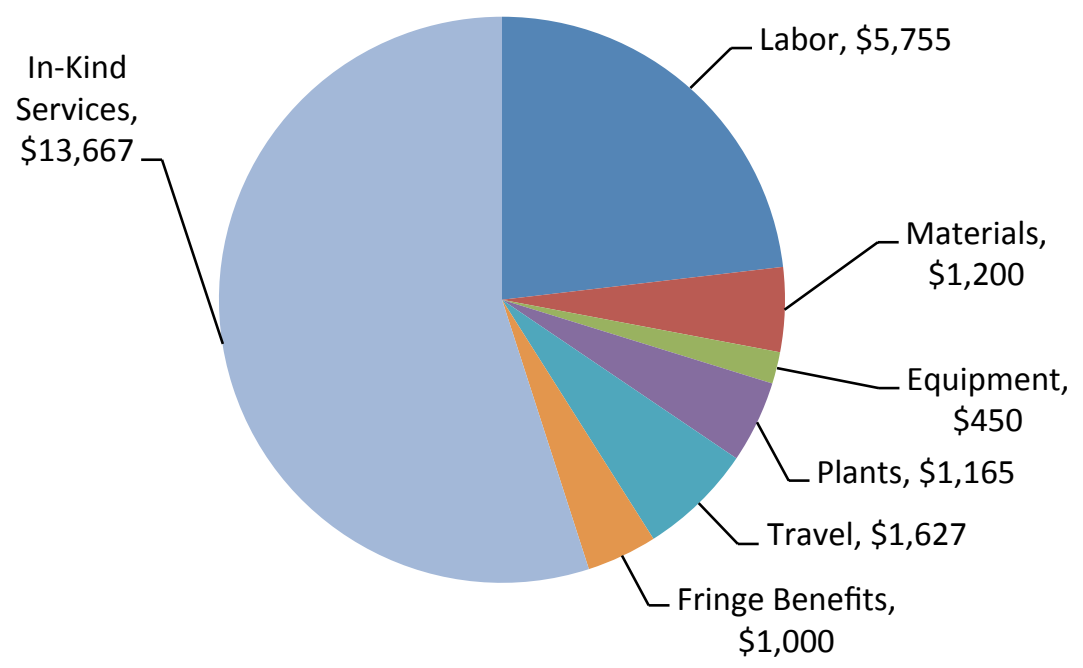

Figure 13 Costs for the Bike Box | Living Roof Lab project $\$ 24,864$ total budget

\section{DISCUSSION}

For educators hoping to incorporate a flexible unit of study for teaching and examining new forms of living architecture, shipping containers can provide both conceptual and applied modes of learning. Each project described here possessed some degree of conceptual idea development that was created by drawing and visualizing living architecture occurring on the container. The first project helps educators with exploratory thinking where context is not prescribed in the assignment. Instead, due to the shipping container movability, the context, program, and living architecture technology can be developed in relationship to one another allowing for a very large range of design ideas. This first project also shows that shipping containers can be coupled to living architecture in short term design problems $(<4$ weeks).

Meanwhile, Projects 2 and 3 help the of design-build educator create a setting for hands-on learning. Project 2 shows how university support and facilities can be used as a testing ground for smaller scale preliminary ideas. The construction of the building skin framework on a permanent facility was a necessary step for proofing the ECOcomponent ideas that will be deployed later on the shipping container. This aids educators and investigators by showing an intermediate step that may be required in some cases. It also shows how preliminary findings can influence the conceptualization of a shipping container. When it comes to curriculum, Project 2 shows instructors how they can incorporate living architecture into the conventional lecture and lab format of 'buildings systems/environmental technologies' courses when teaching the required set of building facade assemblies.

Project 3 helps instructors interested in a team-based experiential learning where students oversee and participate in the construction of their idea. The division of responsibilities from Project Manager to Operations Leader helped realize the various steps of a projects work flow towards completion. The revisions required in fabricating and installing the project required high levels of reflective thinking that are often considered to be excluded in this style of education. Students remarked on an improved clarity of 
understanding the ways living architecture can be designed and constructed for specific goals. When looking for a way to engage students this course helps show how external funding can be used outside student course work. In addition, the project may help fellow professionals, decision makers and the public perceive living architecture and mobile urban infrastructure.

Obstacles do exist; although less refurbishing is needed for creating experimental space when compared to permanent occupation, the shipping containers studied here require reconfiguration in both the conceptual and applied projects. Also, the deployment placement in the public environment can be problematic. For example, in Cleveland, Ohio USA, shipping containers placed in the street R.O.W. must be permitted and moved after short duration. Lastly, the dispersal of sites can make routine data collection difficult for graduate students who must travel long distances to take field samples, so having local participating partners is helpful.

Even given these obstacles, post-use shipping container investigation is contributing to the knowledge base of a movable living architecture through envelop assemblies and strategic urban deployment of ecological systems. These investigations show that various levels investment from universities and faculty are required to initiate and in two cases an additional cash budget was required. Collectively, the projects demonstrate that moving away from retrofit novel housing use of shipping containers towards innovative programs delivering local ecological resources from wall, ceiling and deployable assemblies can contribute to a creative learning environment that can assist with training and investigations in living architecture.

\section{ACKNOWLEDGMENTS}

The ECOmponent (Marietta, GA USA) was incorporated into the curriculum of ARCH3313 within the Architecture department of Kennesaw State University in 2013. Funding was acquired through collaboration with Matt Weand of the Biology Department at Kennesaw State University. Special thanks to the contributions of students Cole Ayers, Francesca Boakye, Patrick Chopson, Michael Diaz, Michael Marvin, Laura Sherman, and Asta Varneckiene as identified in each figure above. Additional thanks go to the instructors and class participants in ARCH 3313 for the integration of the ECOmponent into their coursework.

The Bike Box | Living Roof Lab project (Cleveland, Ohio USA) was facilitated by Land Studios, Rust Belt Design, and sponsored by NEORSD and the Greater Cleveland Partnership. We would like to acknowledge students team members: Clair Markwardt, Neil Reindell, Pasquale Esposito, Josh Thomas, and Jeff Jasinski and the numerous volunteers. 


\section{LITERATURE CITED}

Albert, L. 2013. Under Quarantine: Ivy, Butterfly Bush, Scotch Broom and Their Cultivars Face Tough New State Rules. The Oregonian 2010 [cited 23/03/2013 2013]. Available from http://www.oregonlive.com/hg/index.ssf/2010/03/under_quarantine ivy_butterfly.html.

Arkles, B., Pan, Y., and Kim, Y. M. 2009. "The Role of Polarity in the Structure of Silanes Employed in Surface Modification." Silanes and other coupling agents no. 5:51.

Arnold, M. A., and Young, E. 1991. "CuCO3-painted containers and root pruning affect apple and green ash root growth and cytokinin levels." HortScience no. 26:242-244.

Cube Depot 2017. 17 Awesome way to use shipping containers, http://www.cubedepot.com/resources/17-awesome-ways-to-use-shipping-containers/

Dell 2016. Dell Education model uses technology, solar, and shipping containers https://powermore.dell.com/business/dell-education-model-uses-technology-solar-andshipping-containers/

Dillashaw, Christopher 2008. Shipping Container Homes: The Ultimate Guide to Shipping Containers, Creative Space Publishing 158 pages.

Dunnett, Nigel, et al. 2011. Small green roofs: low-tech options for greener living. Timber Press,

Freight Farms Leafy Green Machine, 2017, https://cdn2.hubspot.net/hubfs/466960/2017\%20Freight\%20Farms\%20Leafy\%20Green\%20 Machine.pdf?t=1486756208051\&submissionGuid=cb4077ae-8059-476a-acf1-cd7816bec564

Greenroof Shelters 2016. Introduction http://greenroofshelters.co.uk/

Hogan, Mark 2015. Opinion: What's Wrong With Shipping Container Housing? Everything http://www.archdaily.com/773491/opinion-whats-wrong-with-shipping-containerhousing-everything

Kramer, Sibylle 2015. The Box: Architectural Solutions with Containers, Braun Publishing, 192 pp.

Ladacour 2014. Ladacour completes largest shipping container-based hotel in North America, http://www.ladacor.com/ladacor-completes-largest-shipping-container-based-hotel-in-northamerica.html

Niedderer, K. and Reilly, L., 2011. Research practice in art and design: Experiential knowledge and organised inquiry. Journal of Research Practice, 6(2), p.2.Schön, D.A., 1987. Educating the reflective practitioner: Toward a new design for teaching and learning in the professions. Jossey-Bass.

Poteet Architects 2017 Container Guest house http://www.poteetarchitects.com/containerguesthouse/1.html

Smith, J. D. 2016. "SHIPPING CONTAINERS AS BUILDING COMPONENTS." Thesis. Ed. Noel Painting. University of Brighton, 2006. SHIPPING CONTAINERS AS BUILDING 
COMPONENTS. Academia.edu. Web. 24 May.

https://www.academia.edu/8671320/SHIPPING_CONTAINERS_AS BUILDING_COMPO NENTS

Tempohousing 2016. Keetwonen (Amsterdam student housing)

http://www.tempohousing.com/projects/keetwonen.html

Preisser, A.M., Budnik, L.T. and Baur, X., 2012. Health effects due to fumigated freight containers and goods: how to detect, how to act. Int Marit Health, 63(3), pp.133-9

Poteet 2016. Container guest House http://www.poteetarchitects.com/containerguesthouse/1.html

Rodrigue, J. P., Comtois, C., \& Slack, B. 2013. 'Repositioning of empty containers' in The geography of transport systems. Routledge https://people.hofstra.edu/geotrans/eng/ch5en/appl5en/ch5a3en.html

Whittinghill' L. J., Rowe’ D. B., Schutzki, R., and Cregg, B. M. 2014. “Quantifying carbon sequestration of various green roof and ornamental landscape systems" Landscape and Urban Planning v.123: 41-48. 